\title{
LA ESCRITURA PUBLICITARIA EN LOS BEATOS: EL CASO DEL BEATO DE URGEL, UNA PRIMERA APROXIMACIÓN
}

\section{PUBLICITY WRITING IN BEATUS MANUSCRIPTS: AN APPROACH TO URGELL BEATUS}

\author{
Natalia RODRÍGUEZ SUÁREZ \\ Universidad Isabel I
}

Resumen: El objetivo de este trabajo es analizar la escritura publicitaria del Beato de la Seo de Urgel. La escritura publicitaria es aquella escritura cuyas características permiten despertar el interés del receptor del mensaje. Por ello, es la empleada en las inscripciones medievales, aunque no es una escritura exclusiva de este tipo de producción escrita, sino que la podemos encontrar también en códices y documentos. Los letreros empleados en el Beato de Urgel resultan simples y sencillos. Un primer acercamiento a la obra nos permite distinguir al menos tres manos en la escritura publicitaria, cada una con sus propias particularidades. Al comparar éstas con la escritura ordinaria comprobamos que en la mayoría de los casos parece tratarse de la misma persona.

Palabras clave: Beatos, Beato de Urgel, Epigrafía medieval, Paleografía, Escritura publicitaria, Codicología.

\begin{abstract}
The objective of this work is to analyze advertising writing of the Beatus Commentary of Seu d' Urgell. Advertising writing is that writing whose characteristics allow the stimulation of the interest of the receiver of the message. For this reason, it is broadly used in the medieval inscriptions, but it is not exclusive to this type of writing, it can also be found in codices and documents. The signs employed in the Urgell Beatus are simple and plain. A first approach to the work allows us to discriminate at least three authors with their peculiarities in the Urgell Beatus. When ordinary writing from the text and advertising writing are compared, is possible to find similarities in the majority of cases that appears to be executed, in both cases, by the same person.
\end{abstract}

Keywords: Beatus, Beatus Commentary; Urgell Beatus; Medieval Epigraphy; Paleography; Advertising writing; Codicology. 


\section{NATALIA RODRÍGUEZ SUÁREZ \\ LA ESCRITURA PUblicitaria EN Los BEATOS: El CASO DEL BEATO DE URGEL...}

Allá por el último cuarto del siglo VIII, el norte de la Península Ibérica estaba enfrascado en plena polémica adopcionista. El arzobispo de Toledo, Elipando, y su teólogo, Felix de Urgel, defendían que Jesucristo, por su naturaleza humana, hubo de ser simplemente hijo adoptivo de Dios. Frente a ellos, los cristianos tradicionales denunciaban esta postura. Uno de los mayores detractores de ese adopcionismo fue el obispo de Osma, Eterio que, a través de un monje del monasterio de San Toribio de Liebana llamado Beato, denunciaba la postura de los herejes ${ }^{1}$. La Epístola de este monje contra Elipando, es fiel reflejo de toda esta situación ${ }^{2}$. Pero ésta no fue la única obra que surgió de la relación de estos dos personajes, hubo otra que alcanzaría una repercusión quizás inimaginada por sus autores. $\mathrm{Me}$ refiero al Commentarium in Apocalypsin, escrito por Beato.

En el IV concilio de Toledo, del año 633, se decretaba la obligatoriedad de leer y explicar el Apocalipsis en todas las iglesias desde Pascua a Pentecostés ${ }^{3}$. La oscuridad y dificultad de interpretación que presenta este texto, pronto llevó a que aparecieran comentarios al libro de San Juan. Parece que fue el obispo Eterio quien solicitó a Beato que realizase un nuevo comentario al Apocalipsis ${ }^{4}$. Para ello, retoma citas de autores anteriores, véase: san Agustín, san Ambrosio, san Jerónimo, san Fulgencio, san Gregorio, Ticonio, san Ireneo, Apringio, y san Isidoro $^{5}$. Tras dos intentos — 776 y 784 - en el año 786 quedó concluida la versión definitiva que incluía una dedicatoria al obispo Eterio ${ }^{6}$.

La obra tuvo una gran repercusión desde el siglo VIII al siglo XIII, copiándose en numerosos scriptoria ${ }^{7}$. Hoy conservamos 36 Beatos, medievales, más dos del siglo XVI, de los cuales 24 estarían casi completos y el resto en estado muy fragmentario, conservando sólo algunos folios sueltos ${ }^{8}$.

${ }^{1}$ F. C. SÁINZ DE ROBLES, Elipando y san Beato de Liébana: siglo VIII, Madrid, 1935. M. CORELLA LACASA, "Notas para una lectura política de la obra del Beato de Liébana", en Res Publica. Revista de Historia de las Ideas Politicas 17, 2007, pp. 9-32.

${ }^{2}$ Cf. Beati Liebanensis et Eterii Oxomensis adversus Elipandum, libri duo, Turhout, 1984. J. GONZÁLEZ ECHEGARAY, A. DEL CAMPO HERNÁNDEZ Y L. G. FREEMAN (eds.), Obras completas de Beato de Liébana, Toledo-Madrid, 1995.

${ }^{3}$ Cf. J. PINELL, Liturgia hispana, vol. 9, Barcelona, 1998, pp. 111 y ss.

${ }^{4}$ H. A. SANDERS (ed.), Beati in Apocalypsim libri duodecim, Roma, 1930, p. 241-242.

${ }^{5}$ Sobre la originalidad de Beato cf. J. A. FERNÁNDEZ FLÓREZ, "Los comentarios al Apocalipsis" en Beato de la Universidad de Valladolid, t. II, Madrid, 2002, p. 122-123.

${ }^{6}$ M. C. VIVANCOS, El apocalipsis de San Juan y Beato. Comentarios al Apocalipsis de Beato de Liébana, Barcelona, 1995, pp. 56-60.

${ }^{7}$ Sobre los distintos beatos cf. V. GARCÍA LOBO, "Beato y los "Beatos" Tradición de un texto medieval "en Actas del XI Congreso Internacional de la Asociación Hispánica de literatura Medieval. (Universidad de León, 20-24 de septiembre de 2005), León, 2007, pp. 65-79.

${ }^{8}$ Entre estos últimos cabría destacar los últimos aparecidos: T. BURÓN CASTRO, "Fragmentos de Beato", en León y su Historia. VI, Miscelanea histórica de temas leoneses, León, 2000, 


\section{NATALIA RODRÍGUEZ SUÁREZ LA ESCRITURA PUblicitARIA EN los BEATOS: El CASO dEL BEATO DE URGEL...}

Uno de esos Beatos es el que se conserva en el archivo de la Seo de Urgel y en él centraré mi estudio de su escritura publicitaria, analizando sus características e intentando discernir si ésta se relaciona o no con la escritura ordinaria del códice.

\section{EL BEATO DE LA SEO DE URGEL: ASPECTOS GENERALES}

La obra está trazada sobre pergamino, en escritura visigótica. Consta de un total de 232 folios. La obra original se vio alterada con la supresión de algunos folios y la adicción de siete hojas introductorias, que presentan una numeración romana.

La escritura ordinaria se traza en tinta negra y roja, colores que junto con el azul también se usaron en la escritura publicitaria. Esos mismos pigmentos se emplearán, además, en las noventa ilustraciones que contiene el Beato.

A diferencia de otros Beatos en los que, a través, bien del laberinto inicial, bien del colofón, se pueden localizar el autor o comitente, el destinatario, el rogatario, el scriptorium e incluso la fecha concreta de la obra, el Beato de la Seo de Urgel carece de esta información. Por ello, sólo con un minucioso estudio codicológico, que preste especial atención a la escritura y a la miniatura, se pueden obtener conclusiones más o menos fiables al respecto. Sin embargo, no es éste el objetivo del trabajo, ni por supuesto entrar en la discusión que desde hace años codicólogos y especialistas en el estudio de las miniaturas mantienen sobre el origen de la obra.

Para su datación, los escasos estudios del códice, en su mayoría superficiales, sitúan la obra a finales del siglo $\mathrm{X}$, entorno a la década de los 70 . Y aunque el códice ya se encontaba entre la lista de obras que se conservaban en la catedral de Urgel en 1147, es evidente que éste no fue el lugar donde se originó el Beato, pues en esta zona se escribía en escritura carolina, y la escritura visigótica de la obra la sitúan en otro marco geográfico. Los intentos de encuadrar en un marco geográfico concreto el códice, no han alcanzado los resultados esperados ${ }^{9}$.

p. 125-139. y A. I. SUÁREZ GONZÁLEZ, "Dos folios de un Beato en el Archivo Histórico Provincial de Zamora", Anuario 2001. Instituto de Estudios Zamoranos Florián de Ocampo, 18, 2001, pp. 287-307.

${ }^{9}$ Sobre una revisión de la clasificación de los Beatos en cuanto a su génesis cf. H. GARCÍAARRANZ, "Génesis de los Beatos" en Miscelania Medieval murciana, XVII, 1992, pp. 173-199. A, SUÁREZ GONZÁLEZ, "El Beato del Archivo Histórico Provincial de Zamora" en Textos medievales. Hispania Sacra, 55, 2003, p. 438. J. A. FERNÁNDEZ FLÓREZ, "El apocalipsis y Beato de Liébana. Los beatos y el Beato de Valcavado", en Beato de Valcavado: Códice conser- 


\section{NATALIA RODRÍGUEZ SUÁREZ \\ LA ESCRITURA PUBLICITARIA EN LOS BEATOS: El CASO DEL BEATO DE URGEL...}

Algunos lo ligan al entorno leonés y otros prefieren situarlo en la zona de la Rioja. Los investigadores que lo conectan con el norte de la península lo hacen centrando su atención en las características de la escritura y, sobre todo, de la iluminación. Así, las estrechas relaciones que presenta la obra con otros Beatos como el de San Miguel de Escalada, Tábara o Gerona y, especialmente, con el de Valcavado, llevan a algunos especialistas a situarlo en el entorno leonés, origen que por otro lado parece ser el más factible ${ }^{10}$. Sin embargo, ciertos detalles de sus miniaturas, como los peces en forma arcaica de algunas iniciales, o las terminaciones en cabeza de pájaro con hoja en el pico de otras, hacen que determinados autores, como Gonzalo Menéndez-Pidal, Neuss, Díaz y Díaz o Klein lo conecten con el entorno riojano, e incluso con la zona Navarra al sur del Ebro $^{11}$.

La dificultad de localización del códice impide igualmente saber quienes fueron el autor y los rogatarios concretos del mismo. Sobre estos últimos, Klein indica, al analizar la escritura ordinaria minúscula del texto, que en el códice intervinieron al menos tres manos distintas ${ }^{12}$. Por su parte el especialista en miniatura J. Williams concluye que el iluminador hubo de ser una única persona, no demasiado experta ${ }^{13}$. Sobre los rogatarios de la escritura publicitaria no existen referencias hasta el momento, por ello, me centraré en ésta con el fin de intentar conocer si el trazado de la escritura publicitaria, que comparte espacio con el texto, se relaciona de alguna manera con el copista de la obra o bien resulta no compartir ningún rasgo con éste, lo que invitaría a pensar que se trata de otra persona.

vado en la Biblioteca del Colegio de Santa Cruz de la Universidad de Valladolid, vol. 2, Valladolid, 1993.

${ }^{10}$ P. BOHIGAS, La ilustración y decoración del libro manuscrito en Cataluña. Contribución al estudio de la miniatura catalana, t. I, Barcelona, 1960, p. 29. WILLIAMS J, The Illustrated Beatus. A corpus of the illustrations of the commentary on the apocalypse the tenth and eleventh centuries, vol III, Londres, 1998. p. 17. J. YARZA LUACES, Beato de Liébana: manuscritos iluminados, Barcelona, 1998, pp. 144-146. J. A. FERNÁNDEZ FLÓREZ, “El apocalipsis...”.

${ }^{11}$ G. MENÉNDEZ-PIDAL, "Mozárabes y Asturianos en la cultura de la Alta Edad Media", en Boletín de la Real Academia de la Historia, 134, 1954, pp. 137-291. W. NEUSS, "Elementos mozárabes en la miniatura catalana", en Homenatge a Antoni Rubió i Lluch. Miscellàni d'estudis literais i linguistics, t. I, Barcelona, Estudis Universitáris Catalans XXI, 1936, p. 507-523. M. DÍAZ Y DÍAZ, "La circulation des manuscrits dans la Péninsule Ibérique du VIIe au XI" siècle", en Cahiers de Civilisation Médiévale, 12, 1969, pp. 383-392, M. DÍAZ Y DÍAZ, "La tradición del texto de los comentarios al Apocalipsis", en Actas del Simposio para el estudio de los códices del "comentario al Apocalipsis" de Beato de Liébana (Madrid, 22-25 de noviembre de 1976), t. I, Madrid, 1978, pp. 163-191. M. DÍAZ Y DÍAZ, Códices visigóticos de la monarquía leonesa, León, 1983, p. 297. P. K. KLEIN, Beato de la Seo de Urgel, volumen de estudio, Madrid, 2002.

12 P. K. KLEIN, Beato..., p. 21.

${ }^{13}$ J. WILLIAMS, The illustrated Beatus..., p. 17. 


\section{EL ANÁLISIS DE LA ESCRITURA PUBLICITARIA Y SU JUSTI- FICACIÓN}

Esta obra permite poner de relieve las relaciones que existen entre dos campos de estudio: la epigrafía y la codicología. La escritura publicitaria es uno de esos elementos que pone en conexión el epígrafe y el manuscrito, aspecto que ya quedó refrendado en numerosos trabajos de los profesores Koch o García Lobo ${ }^{14}$.

Todo epigrafista sabe que un texto para ser considerado inscripción ha de tener un carácter publicitario, es decir, que la finalidad había de ser la de publicitar un mensaje. Así lo percibía ya en 1953 Gómez-Moreno, cuando definía inscripción como: "composición literaria para conmemorar un hecho en condiciones monumentales. Publicidad, solemnidad y perduración la caracterizan"15 y así, esta definición ha seguido siendo puesta de manifiesto por el profesor Favreau que la calificaba de "ce qui est écrit sur un monument ou en objet donné, en vue d'une publicité universelle et durable" ${ }^{16}$. Del mismo modo, también el profesor Vicente García Lobo define inscripción como "Cualquier testimonio escrito en orden a una publicidad universal y perdurable"17.

Para alcanzar dicho fin, el rogatario de la inscripción acudía a distintas técnicas para llamar la atención del receptor del mensaje. Una de esas técnicas consistía en el empleo de una escritura particular, la escritura publicitaria. Las características de esta grafía permiten despertar el interés del receptor del mensaje. Por ello, es la empleada en las inscripciones medievales. Sin embargo, a pesar de que

${ }^{14}$ W. KOCH, "Eine epigraphische Überlieferung einer Urkunde Kaiser Friedrichs II?", en Estudis Castellonencs 6 (1994-1995), pp. 697-708 y W. KOCH, "Epigraphik und die Auszeichnungsschrift in Urkunden", en Documenti medievali Grecia e latini. Studi comparativi. Atti del seminario di Erice (23-29 ottobre 1995), a cura di Giuseppe de Gregorio e Otto Kresten, Spoleto, 1998, pp. 309-326 + 11 taf. V. GARCÍA LOBO, "La escritura publicitaria de los documentos", en De litteris, manuscriptis, inscriptionibus... Festschrift zum 65. Geburtstag von Walter Koch, Wien, pp. 229-255. V. GARCÍA LOBO, "La escritura visigótica publicitaria", en Paleografía I: La escritura hasta 1250. Boletín de la Sociedad Española de Ciencias y Técnicas Historiográficas, Burgos, 2008, pp. 63-91. V. GARCÍA LOBO, "La escritura publicitaria", en Las inscripciones góticas. II Coloquio Internacional de Epigrafía medieval, León del 11 al 15 de septiembre 2006, León, 2010, pp. 29-44.

${ }^{15}$ M. GÓMEZ MORENO, El concepto de la epigrafía consideraciones sobre la necesidad de su ampliación. Discursos leídos ante la Real Academia de la Historia en la recepción pública del primero del día 18 de enero de 1953, Madrid, 1953, p. 93. J. DE SANTIAGO FERNÁNDEZ, "La Epigrafía: evolución conceptual y metodológica", Documenta \& Instrumenta, 1, Madrid, 2004, pp. 203-220. N. RODRÍGUEZ SUÁREZ, "Un repaso a través de los conceptos de Epigrafía e inscripción”, Documenta \& Instrumenta, 10, Madrid, 2012, pp. 147-154.

${ }^{16}$ R. FAVREAU, Les inscriptions medievales, Turhout, 1979, p. 16.

${ }^{17}$ V. GARCÍA LOBO, Los medios de comunicación social en la Edad Media. La comunicación publicitaria. Lección inaugural curso académico 1991-92, León, 1991, p. 17. 
ésta es la escritura comúnmente empleada en los epígrafes, no es una escritura exclusiva de estos, sino que la podemos encontrar también en códices y documentos, donde se utiliza con la misma finalidad que en las inscripciones, llamar la atención del destinatario ${ }^{18}$.

Así pues, queda justificada la inclusión del estudio de la escritura publicitaria de un códice, el Beato de la Seo de Urgel, pues dicha escritura es común para los tres medios de comunicación, —la inscripción, el códice y el documento-

\section{LA ESCRITURA PUBLICITARIA DEL BEATO}

La escritura publicitaria se emplea en los códices en tres lugares preferentemente: en los títulos, — que jerarquizan cada una de las partes del códice, esto es: Incipit, Explicit, Finit, etc-; en las inicales mayúsculas empleadas a lo largo del texto, o en las ilustraciones. Centraremos nuestra atención en los primeros, los títulos, porque los otros letreros publicitarios estarían más ligados al mundo de la ilustración. Así pues, las iniciales miniadas se encuentran más ligadas a la iluminación del códice y lo mismo sucede con los mensajes publicitarios que forman parte de algunas miniaturas. En ambos casos parece que dichos letreros fueron realizados por el iluminador del Beato. Así que, el rogatario de estos mensajes fue el propio iluminador del códice se nos hace evidente en la miniatura de la mujer sobre la bestia del folio 47 vuelto. En la mitad superior de dicha página encontramos la miniatura y en la mitad inferior el texto sobre el pasaje de la mujer y la bestia. Este texto comienza con su título en escritura publicitaria menor que dice: De muliere supra bestia, escrito por el rogatario del códice. Si observamos atentamente la miniatura se ve cómo en la parte superior izquierda el escriba dejó un mensaje al iluminador, indicando qué escena se debía representar, es una pequeña minuta en escritura visigótica minúscula que dice: mulier super - abreviado- bestia. Cuando el iluminador dibujó la escena, consideró que era preciso incluir una explanatio de la miniatura y volvió a repetir el mismo mensaje en escritura publicitaria: mulier supra bestia, texto que, como hemos dicho, resultaba innecesario, pues el copista del códice ya lo había incluido en el texto también en escritura publicitaria.

\footnotetext{
${ }^{18}$ Esta idea ya se ponía de relieve en: V. GARCÍA LOBO, "Epigrafía y filología”, en Actas del II Congreso Hispánico de Latín Medieval, León 10-14 de noviembre de 1997, vol. I, León, 1999, pp. 61-72, cuando al hablar de los Títulos, Incipits y Explicits, decía: "Esta escritura, generalmente mayúscula, tiene una funcionalidad muy concreta, la de «llamar la atención», "hacer notorio» lo que allí se dice. Es, pues, una escritura de «notoriedad», una escritura publicitaria".
} 
De la misma manera, las iniciales miniadas, son fruto de un rogatario distinto al que realizó la escritura ordinaria. Las características de estas letras, muy decorativas, casi dibujadas, hacen suponer que fue un iluminador el encargado de llevarlas a cabo. De hecho, el propio códice nos advierte - en los folios $21 \mathrm{v}, 22 \mathrm{v}$ o $52 \mathrm{v}$ - que estas iniciales no se hicieron a la vez que se copiaba el texto del Beato, sino con posterioridad, y que ni siquiera fueron llevadas a cabo por el rogatario que realizó la escritura publicitara, pues en esos folios se aprecia que faltan esas iniciales decoradas, y, sin embargo, el texto publicitario sí se copió.

Por todo ello, únicamente analizaré los títulos publicitarios del códice, pues pretendemos llegar a saber cuántos rogatarios intervinieron en la realización de esta escritura publicitaria, cuáles serán sus particularidades gráficas y en qué medida serán los mismos que los copistas del Beato, dejando de lado al posible iluminador del códice.

\section{LOS TÍTULOS Y SUS CARACTERÍSTICAS GENERALES}

Para la catalogación de estos letreros he seguido la tipología propuesta por la profesora Martín López en su estudio de la escritura publicitaria del Codex Biblicus legionensis ${ }^{19}$. Así, los letreros se clasifican en: solemnes, semisolemnes, comunes y menores.

Al analizar el Beato de la Seo de Urgel rápidamente percibimos que sólamente se emplearon letreros semisolemnes, comunes y menores, ya que los tituli solemnes son meramente anecdóticos, como veremos. Además, es habitual que en un mismo título se combinen varios tipos de letreros, siendo muy usuales los que comienzan desarrollando el mensaje en tipos comunes y lo concluyen en menores. Es difícil llegar a conocer con certeza porqué el rogatario utilizá esta distribución, cuando es evidente que no se emplea como método de jerarquización del texto. Quizás sea éste un elemento estético o una manera de ahorrar espacio, o tal vez sea una técnica para facilitar al ojo del lector adecuarse a la escritura visigótica minúscula del texto, y así vemos cómo, en la primera línea, se emplean los títulos semisolemnes, en una segunda línea se continúa en caracteres comunes, para pasar luego a los menores, antes de continuar el capítulo en escritura visigótica minúscula (fig. 1).

\footnotetext{
${ }^{19}$ Ma. E. MARTÍN LÓPEZ, "La escritura publicitaria”, en Codex Biblicus Legionensis. Veinte estudios, León, 1999, p. 127. Dicha clasificación fue seguida también por: V. GARCÍA LOBO, Beato de Tábara, Madrid, 2005.
} 


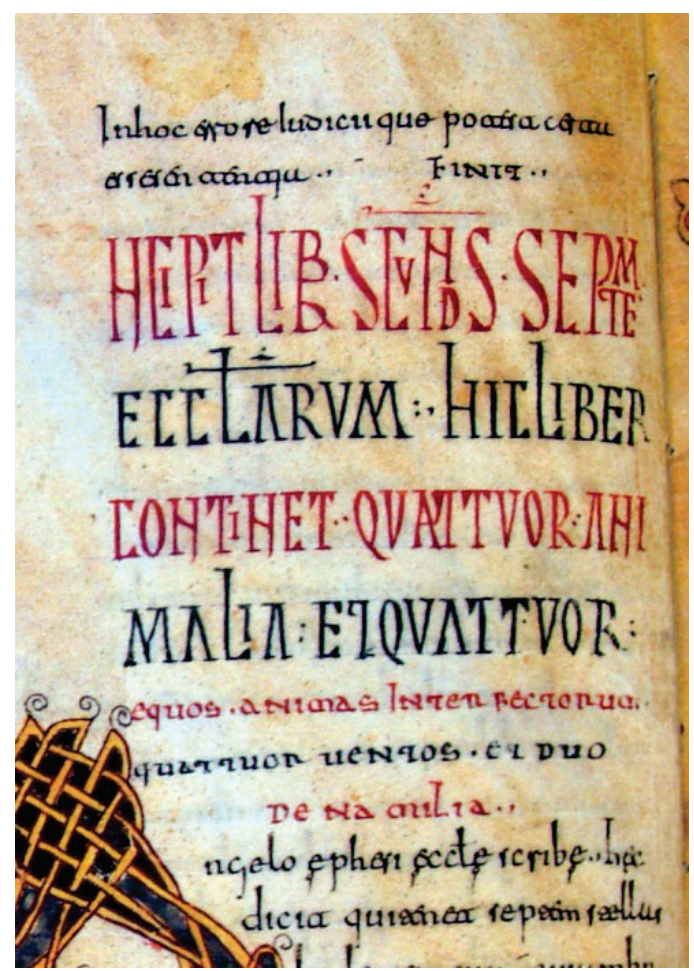

Fig. 1. Beato de Urgel. Transición de la escritura publicitaria. Fol. 52 vuelto.

El adjetivo que mejor describe los letreros empleados en el Beato de Urgel es el de simples o sencillos. Resultan sencillos porque ni las letras ni el pautado aparecen perfilados, lo que resaltaría y enriquecería los títulos, como sucede en Beatos como el de San Miguel de Escalada, o el de Tábara. Tampoco se colorean los bucles de las letras, como ocurre en ciertos Beatos como, por ejemplo, el propio de Valcavado. Por todo ello, resultan unos títulos simples.

Las tintas empleadas son las comunes, el rojo y el negro, que en ocasiones se sustituye por el azul; mientras que otros pigmentos, también usuales en los Beatos, como el amarillo o el verde, se reservan para el iluminador de las iniciales miniadas y no para nuestro rogatario. El Beato de la Seo de Urgel únicamente emplea como técnicas decorativas, en la escritura publicitaria, la combinación de pigmentos en los títulos, bien por líneas, bien por palabras, e incluso en alguna ocasión por letras. Es ésta una técnica decorativa, que abarata el coste del códice y le confiere esa sencillez a la que aludía.

Si ligamos estas características de la escritura publicitaria, con las particularidades del iluminador, al que califican de poco $\operatorname{avezado}^{20}$, las del rogatario de la escritura visigótica minúscula, en la que observamos continuos

\footnotetext{
${ }^{20}$ J. WILLIAMS, The illustrated Beatus..., p. 17.
} 
errores $^{21}$, y la presencia de numerosas partes inconclusas: textos, iniciales, miniaturas, podemos concluir diciendo que el Beato de la Seo de Urgel es un Beato pobre.

\section{LA CLASIFICACIÓN DE LOS TITULI}

En orden a una jerarquía de tamaño, los tituli solemnes serían los formados por letras de gran módulo, que superan las dos unidades de pautado. Dichos letreros solemnes, se presentan en nuestro códice de manera meramente anecdótica, esto es así porque únicamente aparece uno en todo el códice. En el folio 152 verso encontramos un Incipit Magister en tinta roja que supera las dos unidades de pautado en medio pautado más. Al ser un único caso, y la variación del módulo tan pequeña respecto a los letreros semisolemnes, se convierte en "la excepción que confirma la regla".

En cuanto a los letreros semisolemnes éstos tienen un módulo ligeramente menor que los anteriores, ya que se enmarcarán en dos unidades de pautado. El uso de la escritura semisolemne es habitual en el texto; se emplea en ochenta folios, distribuídos de la siguiente manera: cincuenta y siete "Incipit", veintiseis Explanationes, siete "Explicit" y y cinco letreros más que son: In nomine Domini nostri Ihesu Christi incipit (fol. 1v), un Incipit cuyas dos primeras palabras se desarrollan en escritura solemne y continúa con Laterculi hunius et rationa literarum en escritura semisolemne (fol. 151v), un Qualiter cognoscatur antichristus in toto mundo (fol. 152v), un In nomine Domini nostri Ihesu Christi Explanatio (fol. 195v), un Per sub divisio visionis (fol. 220v), y un Incit visio hoctaba... (fol. 222). ${ }^{22}$.

Un análisis más detenido muestra cómo en la primera parte del códice su utilización es mucho menor, y al avanzar en el texto el número de letreros que emplea este tipo de escritura publicitaria se multiplica. Quiza éste uso esté relacionado con la presencia de distintos rogatarios y las preferencias particulares de cada uno de ellos.

\footnotetext{
${ }^{21}$ Son numerosos los folios en los que los rogatarios olvidan palabras o frases completas y han de realizan numerosas llamadas para subsanar el error.

${ }^{22}$ Fols. 1v, 15, 21v, 22v, 42v, 52v, 85v, 123v, 124, 125v, 126, 127, 127v, 128v, 129v, 130, $130 \mathrm{v}, 131,131 \mathrm{v}, 132,133 \mathrm{v}, 135,135 \mathrm{v}, 136,137,138,139,139 \mathrm{v}, 141 \mathrm{v}, 144,145 \mathrm{v}, 147 \mathrm{v}, 148$, $151 \mathrm{v}, 152 \mathrm{v}, 154 \mathrm{v}, 155 \mathrm{v}, 156,158,158 \mathrm{v}, 159 \mathrm{v}, 160 \mathrm{v}, 162,163,163 \mathrm{v}, 164,164 \mathrm{v}, 165,166,166 \mathrm{v}$, $167 \mathrm{v}, 168,168 \mathrm{v}, 172,172 \mathrm{v}, 173 \mathrm{v}, 174 \mathrm{v}, 176,177 \mathrm{v}, 178,178 \mathrm{v}, 179 \mathrm{v}, 180 \mathrm{v}, 181,181 \mathrm{v}, 182 \mathrm{v}$, $185 \mathrm{v}, 187 \mathrm{v}, 191 \mathrm{v}, 193,195 \mathrm{v}, 196,198 \mathrm{v}, 201,204,210 \mathrm{v}, 214,215 \mathrm{v}, 220 \mathrm{v}, 222$.
} 
Los tituli comunes son los letreros que se emplean normalmente en los códices, de ahí su nombre. En ellos, el módulo no supera la unidad de pautado. En sesenta y seis folios de nuestro códice aparecen letreros con este tipo de escritura; en cuarenta y cinco de ellos, la encontramos como escritura principal, mientras que en los veintiuno restantes completan letreros que comenzaron en escritura semisolemne ${ }^{23}$. De los que emplean la escritura común como escritura principal, treinta y cuatro son Incipits, cinco son Explanationes y cuatro Explicits; además, encontramos un Prolocus Beati Iheronimi in libro Apocalipsin Ihoannis/ Item domini Iheronimi in explanatione (fol. 2), un Praefatio (fol. 15v), un Interpretatio qualiter una ecclesia sit cum septem (fol. 82), De antichristo qualiter imperatorem tollat romanum (fol. 153).

El porcentaje es muy similar al de la escritura semisolemne, advirtiendo, además, que el empleo de ésta cae, en función del mayor uso de la escritura semisolemne que ya indicamos más arriba.

Para finalizar se denominan menores los letreros cuyo módulo es similar al empleado por la escritura minúscula ordinaria. Éste es el tipo de escritura más utilizado por el rogatario del códice de Urgel. Ello se debe a que muchos títulos que comienzan tanto en escritura semisolemne como en escritura común concluyen el mensaje en escritura menor. A ellos hemos de sumar los letreros que se realizan sólamente en escritura menor, pues la sencillez del códice hace que el rogatario prefiera utilizar la escritura menor en la mayoría de los "Finit". Excepcionalmente tenemos ciertas palabras en el interior del texto que utilizan esta forma publicitaria para destacar. Esto sucede especialmente a partir del folio 200 .

\section{LOS ROGATARIOS DEL TEXTO}

El análisis de los caracteres de la escritura publicitaria del códice es el elemento que permite al investigador sugerir la presencia de uno o más rogatarios, en función de la evolución o cambio de los caracteres gráficos, a lo largo del texto. Un primer acercamiento al Beato de Urgel nos permite distinguir al menos tres manos (fig. 2):

${ }^{23}$ Fols: 2, 15, 15v, 16v, 18v, 19v, 34v, 53v, 57v, 58, 62, 63, 66, 67, 70, 70v, 74v, 75, 80, 80v, $82,85,86 \mathrm{v}, 88 \mathrm{v}, 89 \mathrm{v}, 103,104,105 \mathrm{v}, 106,109,110 \mathrm{v}, 112 \mathrm{v}, 113,113 \mathrm{v}, 137 \mathrm{v}, 138 \mathrm{v}, 140,153$, $154,157,159 \mathrm{v}, 176 \mathrm{v}, 180,183,184$. Los letreros comunes que acompañan a la escritura semisolenme son: fols. $42 \mathrm{v}, 52 \mathrm{v}, 85 \mathrm{v}, 123 \mathrm{v}, 124,127,130,132,131 \mathrm{v}, 132,133 \mathrm{v}, 135,135 \mathrm{v}, 138,139$, $144,145 \mathrm{v}, 164,185 \mathrm{v}, 201,204$. 


\begin{tabular}{|c|c|c|c|c|c|c|}
\hline & \multicolumn{2}{|c|}{ MANO A } & \multicolumn{2}{|c|}{ MANO B } & \multicolumn{2}{|c|}{ MANO C } \\
\hline & Publicitaria & Ordinaria & Publicitaria & Ordinaria & Publicitaria & Ordinaria \\
\hline $\mathbf{A}$ & 11 & & $d A$ & & 11 & \\
\hline B & B & & & & B & \\
\hline D & & $\partial_{1}$ & & $\delta$ & f & 0 \\
\hline $\mathbf{E}$ & E & f? & $f$ & & $E$ & e \\
\hline $\mathbf{M}$ & $M$ & & $M_{M}$ & & & \\
\hline $\mathbf{N}$ & N & & $N$ & & N & \\
\hline $\mathbf{P}$ & & p to & & $p$ क & & $p$ \\
\hline $\mathbf{R}$ & R & $r$ & $\mathrm{RB}$ & r. & $R$ & $\sigma_{1}$ \\
\hline$T$ & I & $a_{i}$ & 917 & & 1 & \\
\hline $\mathbf{V}$ & V & & & & $V$ & \\
\hline
\end{tabular}

Fig. 2. Tabla con las letras típicas de los distintos rogatarios.

Una primera mano - mano A - es la que encontramos fundamentalmente en la primera parte del códice. Su escritura es ordenada, recta, bien proporcionada, que salvo en letras como la $\mathbf{N}$, no suele sobrepasar la caja de escritura con elementos decorativos. Precisamente será ésta una de las letras diferenciadoras de este rogatario. Es una $\mathbf{N}$ cuyo travesaño central no arranca de la parte superior del primer trazo, sino que lo hará desde un poco más abajo y concluye en la mitad del segundo, que a su vez termina en una punta que sobresale por debajo de la caja de escritura. Junto a ésta también resultan típicas una $\mathbf{R}$ cuyo segundo y tercer trazo se unen al primero, y aparecen pegados salvo cuando inscribe una letra; la $\mathbf{A}$ mayúscula sin travesaño, conviviendo con una $\mathbf{A}$ con travesaño; la preferencia por la $\mathbf{E}$ cuadrada; la $\mathbf{T}$ con el travesaño superior recto y rematado en puntas hacia abajo, combinada con otra $\mathbf{T}$ rematada en bucle a la izquierda menos habitual y una $\mathbf{V}$ que cierra un poco sus extremos y remata en una gran punta, lo que la convierte en estilizada (fig. 3). Este primer rogatario copiará el códice hasta alcanzar el folio 123, para posteriormente regresar en los folios 157 vuelto y 158 . 


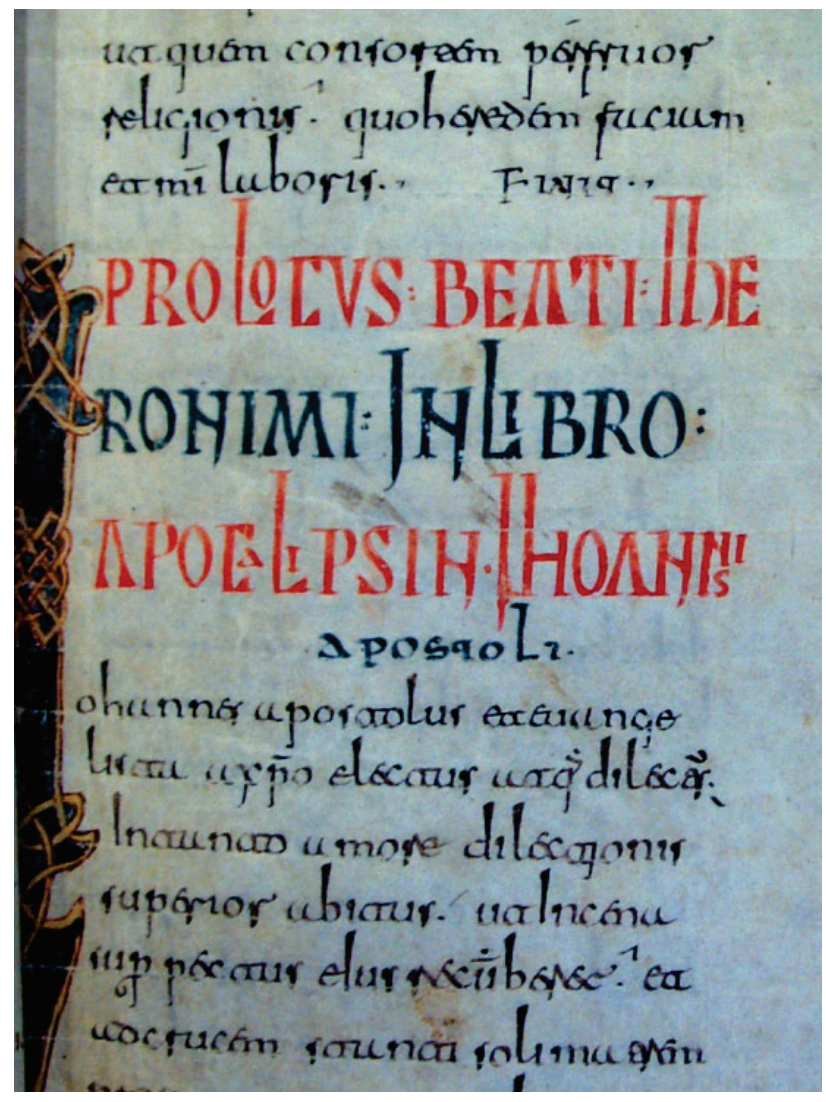

Fig. 3. Beato de Urgel. Mano A. Fol. 2.

Esta mano A que traza los letreros se corresponde a su vez con un único rogatario del texto ordinario que escribe en esas mismas páginas. Ese copista del texto ordinario se caracteriza por la presencia de unos astiles que se vuelven a la izquierda; un signo de per que remata en espiral, las $\mathbf{r}$ finales de martillete, o la e cuyo trazo central se vuelve hacia arriba. También encontramos a este rogatario en los folios 157 vuelto y 158 .

Una mano distinta - mano B - es la que aparece a partir del folio 123 . Resulta una escritura más estilizada, y más decorativa, con preferencia por los bucles en los remates. Sus letras típicas son: la $\mathbf{A}$ minúscula agrandada, la $\mathbf{E}$ minúscula agrandada y la preferencia de la $\mathbf{A}$ minúscula agrandada nexada a la $\mathbf{E}$ minúscula. Junto a ellas, serán peculiares otras letras como la $\mathbf{B}$ que separa sus bucles; la $\mathbf{M}$ algo más abierta que la de la primera mano y cuyo trazo central baja ligeramente por debajo de la caja de escritura, la $\mathbf{N}$ cuya parte central comienza en la parte alta del primer trazo; la $\mathbf{R}$ que o bien separa los trazos dos y tres, o bien se realiza con dos únicos trazos, donde el segundo, al terminar la curva, se separa del primer trazo, la preferencia de la $\mathbf{T}$ con bucle, o el empleo de la $\mathbf{U}$ uncial.(fig. 4). 


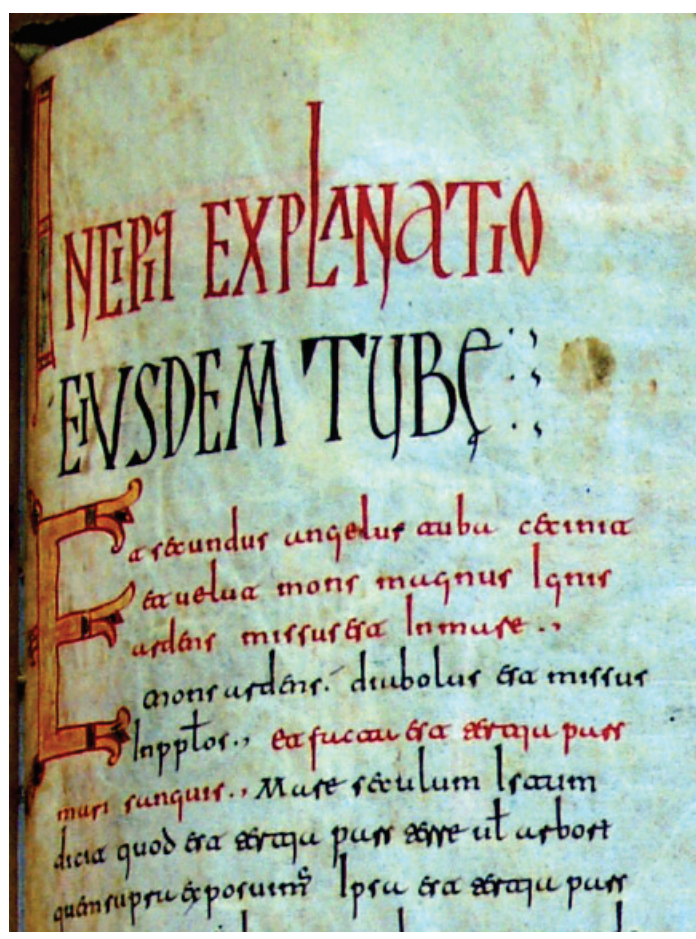

Fig. 4. Beato de Urgel. Mano B. Fol. 130.

Esta mano encaja con un nuevo rogatario de la escritura ordinaria. Este segundo rogatario continúa utilizando como abreviatura de per con bucle, pero su $\mathbf{r}$ será distinta, alargada hacia arriba; también son típicas la $\mathbf{d}$ uncial, con el astil alto, o la e que recuerda a una e mayúscula, pues se realiza a partir de dos trazos, el primero curvo que se mete un poco a la derecha, y el segundo con el que se desarrolla el travesaño de la e y la curva final.

A partir del folio 151 vuelto se nos presenta un tercer rogatario - mano C - La característica distintiva de este rogatario es la presencia de una escritura temblona y algo desordenada. En muchos rasgos, la letra es similar al de la mano A; sin embargo, se advierten algunas divergencias, como la tendencia de los remates de las letras a caer ligeramente por debajo de la caja de escritura. Recuperamos algunas de las grafías que vimos en el primer rogatario como la $\mathbf{A}$ sin travesaño, la $\mathbf{N}$ cuyo trazo central no arranca desde el extremo del primer trazo, y que concluye por debajo de la caja de escritura, o la $\mathbf{V}$ muy estilizada. Sin embargo vemos que combina la $\mathbf{R}$ con bucle separado, con la $\mathbf{R}$ que nexa al primer trazo, la $\mathbf{B}$ separa los dos bucles, y en la $\mathbf{M}$ el trazo central no llega a tocar el final de la caja de escritura.

En torno al folio 180 se aprecia, una mayor torpeza: no calcula el espacio, y la proporción de las letras es desigual; esa misma torpeza se distingue también en 
la escritura ordinaria del folio, olvidando frecuentemente palabras, que coloca luego en el interlineado, abandonando, en muchos folios, la doble columna, presentando el texto a línea tendida y la propia escritura resulta torpe; sin embargo, la forma de las letras resulta la misma. Resulta un rogatario poco cuidadoso. Quizás se trate de una persona entrada en años, y de ahí la letra temblona (fig. 5).
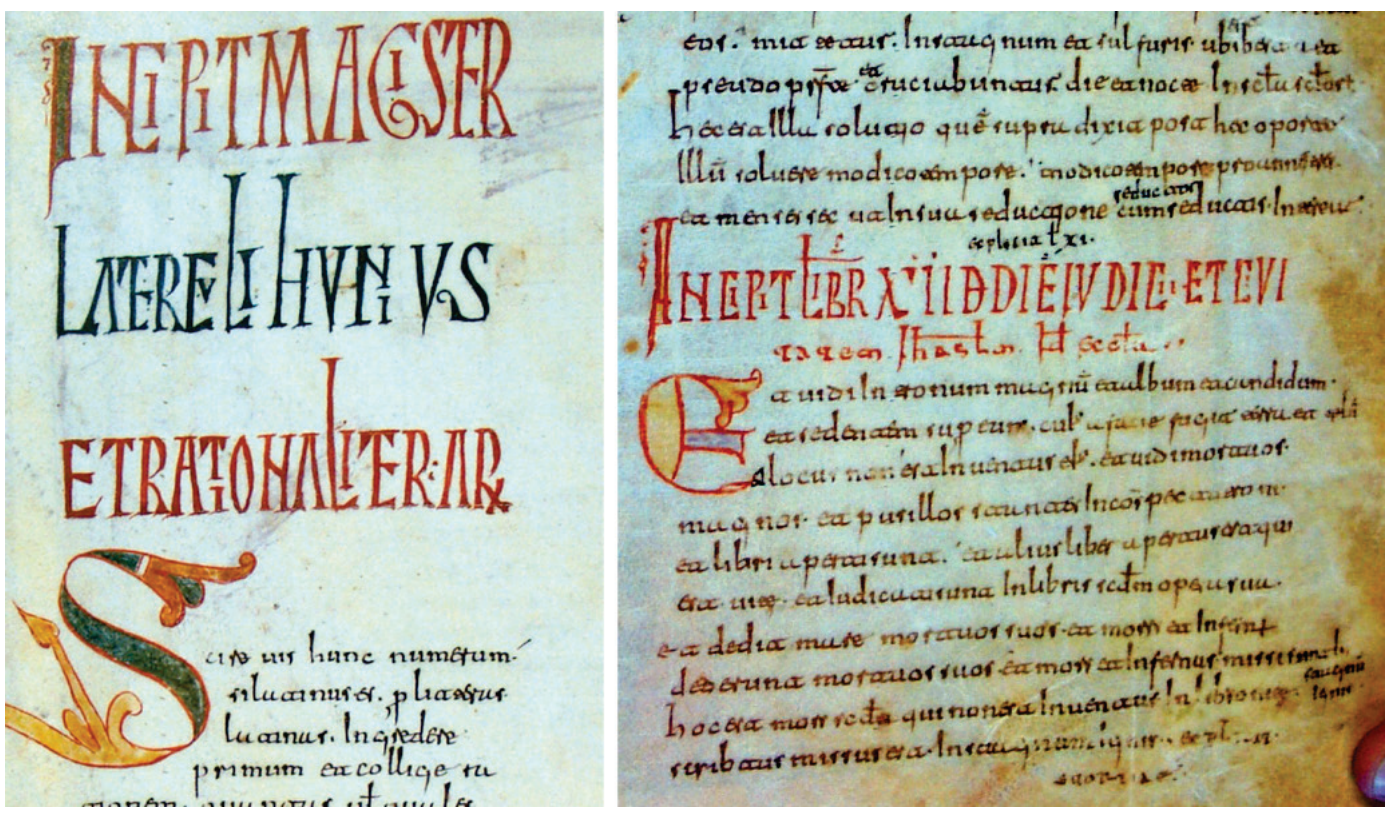

Fig. 5. Beato de Urgel. Mano C. Fols. 152 vuelto y 184.

La escritura ordinaria de estos folios se caracteriza por: la presencia de un per de gancho, el uso de los astiles terminados en triángulo, a modo de la letra aragonesa, la $\mathbf{r}$ con el último trazo no demasiado desarrollado, una $\mathbf{d}$ uncial muy achatada, y la combinación de una e caudata tradicional con otra con un gran circulo. La presencia de un único rogatario de la escritura ordinaria en esta última parte del códice afianza aún más la idea de que el rogatario de la escritura publicitaria es de nuevo el mismo que el de la escritura publicitaria de esta parte del códice.

Así pues, el breve análisis realizado a la escritura publicitaria de este Beato muestra que hubo tres rogatarios publicitarios, que se relacionan, además, con los copistas de la escritura ordinaria, lo que sugiere que si bien la escritura publicitaria en las inscripciones contaba, en muchas ocasiones, con un especialista en la realización de este tipo de escritura, en el caso de la escritura de este códice será el mismo copista, quien se encarga de ambas tareas, pues su conocimiento de la escritura le permite cubrir a la perfección ambas demandas. 